\title{
The Analysis of Multi-Apartment Residential Buildings Energy Consumption in Russia
}

\author{
Aleksandr Lanko ${ }^{1,1^{*}}$, Francisco José Sánchez de la Flor ${ }^{1}$, and Yuri Geraskin ${ }^{2}$ \\ ${ }^{1}$ Department of machines and thermal engines, School of Engineering, University of Cadiz, Av. \\ Universidad de Cádiz 10, 11519 Puerto Real, Cádiz, Spain \\ ${ }^{2}$ Moscow State University of Civil Engineering, 26, Yaroslavskoye shosse, Moscow, \\ 129337, Russia
}

\begin{abstract}
The main reasons for the high energy consumption of residential multi-apartment buildings in Russia are the lack of motivation of developers in the construction and equipment of new buildings with a high energy efficiency class, as well as the insufficient number of energy metering devices. The main solution to the problem may be state support for energy-efficient technologies, compensation for excessive costs of the developer.
\end{abstract}

\section{Introduction}

The purpose of this article is to identify the main reasons for high energy consumption in multi-family residential buildings (MRB) in Russia and suggest ways to improve the energy efficiency of buildings.

The main basic indicators for energy accounting in the residential sector in Russia are the Specific consumption of heat and electricity per 1 square meter per year. Thermal energy consumption refers to the cost of energy for heating and hot water supply. Electrical energy consumption refers to the cost of lighting and the operation of various household appliances. Unfortunately, these indicators are too generalized. For example, they includes the cost of transporting energy, which in the case of thermal energy can reach $20 \%(10 \%$ on average in Russia) of the actual cost of the building [1]. Nevertheless, they are quite revealing.

According to CENEF-XXI, the share of hot water supply accounts for about $60 \mathrm{KW} / \mathrm{h}$ of heat energy per year [2], so heating is the main energy consumed by residential buildings. Energy consumption in the residential sector exceeds the European average $[3,4]$ , even when compared with countries with similar climatic conditions. The main goal is to show the reasons for such high consumption and suggest solutions.

\footnotetext{
* Corresponding author: alexandr.lancko@yandex.ru
} 


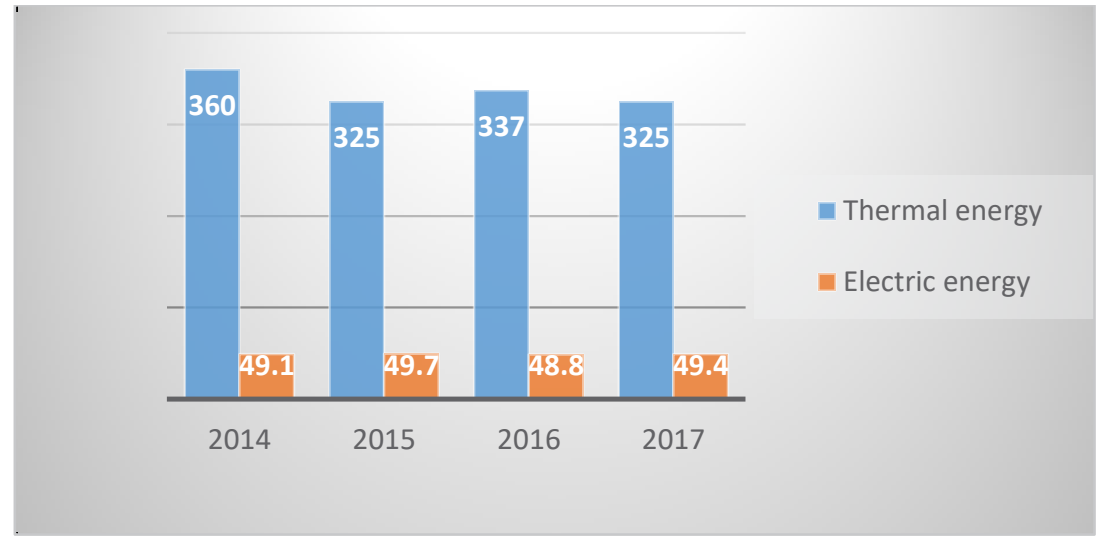

Fig. 1 MRB Specific energy consumption for square meter per year, KW/h

\section{Sources of information}

For analysis of energy efficiency in the sector of residential buildings this article was used specific indicators of energy consumption, calculated on the basis of statistical observation No. 22-ZHKH "Data on the housing and utilities organizations in the conditions of reform" [3]:

- specific consumption of heat energy in apartment buildings

- specific consumption of electrical energy for a block of flats.

Information on indicators of form No. 22-housing and utilities began to be collected in 2014 as a result of the joint work of Rosstat and the Russian Ministry of energy to improve the statistical monitoring system. Accordingly, the values of these indicators can be calculated from 2014, but information about the values of indicators for earlier periods is not available.

The second group of information sources is the official annual reports of various Russian ministries, such as the Ministry of economic development, the Ministry of Energy, and others [7-15].

The third group of information sources are reports of various international organizations involved in collecting statistical data [2-5].

\section{The main problems of low energy efficiency of MRB in Russia and ways to solve them.}

\subsection{Weak construction rates for energy-efficient homes.}

Significant effect of saving energy resources in the residential sector is achieved by introducing technologies with high energy efficiency. Such technologies are used in the construction of MRB with higher energy efficiency classes and in the reconstruction (major repairs) of existing housing stock: installation of thermal insulation of enclosing structures, energy-efficient equipment with metering devices (collective and individual) of energy resources, installation of automated remote collection of resource consumption indicators, installation of Individual Heat Point (IHP) with automatic weather control of the temperature of the coolant, etc.

In the Russian Federation for the end of 2018, there are 1110977 multi-family residential buildings (MRB). Among them, 598,730 MRB (54\%) with a reduced energy 
efficiency class (E, F, G), as well as with an uncertain energy efficiency class. In 2018, 3,636 multi-apartment buildings with a preliminary energy efficiency class of at least $\mathrm{C} 1$ were put into operation, which accounted for $27 \%$ of the total number of MRB commissioned in the country (13,457 units) (figure 2). The vast majority of MRB put into operation are houses with high energy consumption.

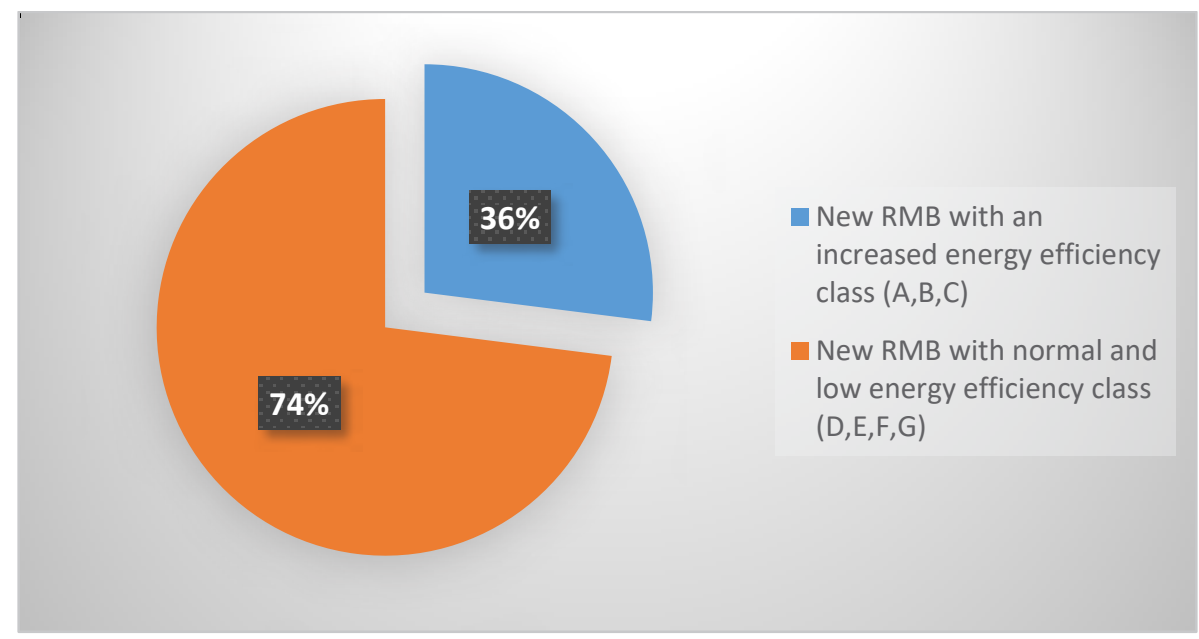

Fig. 2. Share of energy-efficient MRB in new building construction in 2018, percent.

Buildings with the highest class (A++, A+) of energy efficiency consume 50-60\% less energy resources than buildings with normal class (D) in the region under similar conditions, buildings with high class (A, B) - by 30-50\%, buildings with higher class (C) - by $15-30 \%$. The amount of utility payments in these homes is less than in homes with lower energy efficiency classes. The cost of energy-efficient MRB with energy efficiency class $(\mathrm{A}++, \mathrm{A}+, \mathrm{A}, \mathrm{B}, \mathrm{C})$ is $10-25 \%$ higher than the cost of MRB with normal (D) and Reduced (E, F, G) energy efficiency classes. At the same time, utility bills in energyefficient MRB are 30\% -60\% lower than in MRB with normal or reduced energy efficiency class. Thus, the additional cost of an energy-efficient MRB is paid off by saving on utility bills.

\subsection{Why is the construction of energy-efficient not profitable for the developer?}

The problem is that the payback period for investment in energy-efficient homes is too long. Of course, it is very different in the different regions of the country. In regions with low real estate prices and high utility bills (for example, in the North of the country), the payback period is much lower than in the South of the country, where housing prices are higher and the need for heating is much lower. As an example, we can make a calculation for the city of Saint Petersburg, which occupies the 2nd place in the country in terms of the rate of construction of MRB (6.59 million sq. m. per year). On average, $1 \mathrm{~m} 2$ of housing costs 110 thousand Russian rubles, which at the time of writing is about 1200 euros. Utility bills per 1 square meter are around 17 euros per year. Thus, an increase in the cost of an apartment by $20 \%$, while reducing utility bills by $40 \%$, will pay for itself in 35 years. For the Russian economy, this is a very long payback period. It is extremely difficult for a real estate developer to find clients who are willing to seriously overpay when buying real estate in order to save money in the future. Of course, the decision to buy an apartment in a 
building with an increased energy efficiency class is influenced not only by the price of real estate and the benefits of saving on utility bills. Researchers from several countries analyzed the desire of buyers to overpay for energy-saving real estate on the example of the Santiago de Chile market. The results suggests that there is a number of potential home buyers ready to pay for energy efficiency when they are informed on the cost savings associated to structural modifications and the cost of providing such improvements and such willingness to pay is not monolithic across the respondents, but seems to be influenced by the education level plausibly associated to the purchase power[16].

The main way to solve this problem is to encourage developers to build energy-efficient buildings, and consumers to purchase them. At the moment, there is a program to compensate part of the cost of utility payments to residents of houses with an increased energy efficiency class. Unfortunately, this program is not very effective, since the cost of paying energy bills is too small compared to the cost of buying an Apartment. The state's affordable housing program does not prohibit the construction of cheaper buildings with high energy consumption. Thus, the only way out, from the point of view of the authors of the article, is a state program to compensate developers for excessive costs for the construction of an MRB with a high class of energy efficiency.

\subsection{Individual heat points with automatic weather temperature control}

The greatest effect of saving energy resources in the residential sector is achieved through major repairs of the MRB with the introduction of complex of energy-efficient technologies. The ability to regulate the temperature of the heat carrier depending on the temperature of the outside air is the main technology for efficient use of energy resources in a residential building. It is proved experimentally and computationally that the introduction of this technology can reduce the consumption of thermal energy by up to $35 \%$ [8].

In 2018, the share of MRB equipped with Individual heat point (IHP) with automatic weather control of the coolant temperature increased by $1 \%$ compared to 2017 and amounted to $5 \%$ [15]. A slight increase in the volume of implementation is due to the relatively high cost of this technology. In 2018, the number of MRB that underwent major repairs using automated temperature control increased by $8 \%$ compared to 2017 , which indicates a positive growth trend in the provision of buildings with automatic individual heating points. Despite the positive trend, the vast majority of MRB still do not have automatic adjustment of the coolant depending on weather conditions. As a result of manual adjustment, cases of increased temperature in residential buildings are frequent, which leads to unnecessary energy costs. In the case of incorrectly selected low temperature of the coolant, the temperature in the building decreases, causing discomfort. The automatic temperature control system of the heat carrier requires a global modification of the heating system in the MRB and is expensive. However, the payback period for such devices in large MRB is relatively short. Unfortunately, most residents of the MRB are not sufficiently aware of the possibilities of such systems. Residents should be interested in installing an automatic system.

The solution to this problem will also be direct financing of the conversion of existing buildings and compensation for the cost of automation of new MRB from the state at the expense of budget funds.

\subsection{Insufficient equipment for energy resources metering devices}

By the end of 2018, the overall level of equipment for the MRB with collective metering devices was $66 \%$. Including by types of consumed resources: electric energy $71 \%$, heat energy $61 \%$, hot water $65 \%$. Compared to 2017 year, the increase in equipment for the 
MRB collective metering devices accounted for $0.41 \%$. Despite the positive trend, the level of equipment with energy metering devices is very low. This is especially true for thermal energy - the main consumed energy. The lack of household metering devices leads to inefficient use of energy resources. If there are no collective metering devices, energy for collective-purpose needs is paid the same at the maximum rate, regardless of actual consumption. Management companies in MRB lose motivation to minimize energy consumption, which leads to inefficient, often highly inflated energy costs.

According to the results of 2018, the level of MRB equipment with individual heat metering devices was $18 \%$. This is due to the obligation of developers to equip individual heat metering devices only for apartment buildings under new construction. The level of equipment with individual metering devices for hot water $-81 \%$, electric energy $-96 \%$. The level of equipment of individual heat meters is critically low. $82 \%$ of residents in Russia pay for heat at an average rate, regardless of actual consumption. Without motivation to reduce energy costs for heating, it is impossible to achieve a real reduction in energy consumption.

In this case, the problem is not only the high cost of individual heat meters, but also the lack of a real opportunity for individual apartment owners to install a heat meter. According to the rules of the company that supplies heat energy (as a rule, this is a monopolist and the apartment owner does not have the option of choosing a supplier company), all apartments in the MRB must be equipped with individual metering devices. In other words, if an individual apartment owner wants to install a heat meter, he will have to convince all apartment owners in their MRB to install metering devices and issue a collective application for their installation. This procedure is complex and time-consuming. Of course, this rule does not exist in all companies in Russia. In Saint Petersburg, the second largest city with a population of over 5 million people, this problem exists in buildings which were built more than 20 years ago.

To solve this problem, from the authors ' point of view, it is necessary to change the rules of the energy supplier company, which is profitable to accept payment at an average, often inflated tariff. The authors are confident that the widespread installation of heat metering devices will create motivation for the population to save it and will allow for much more efficient use of heat energy

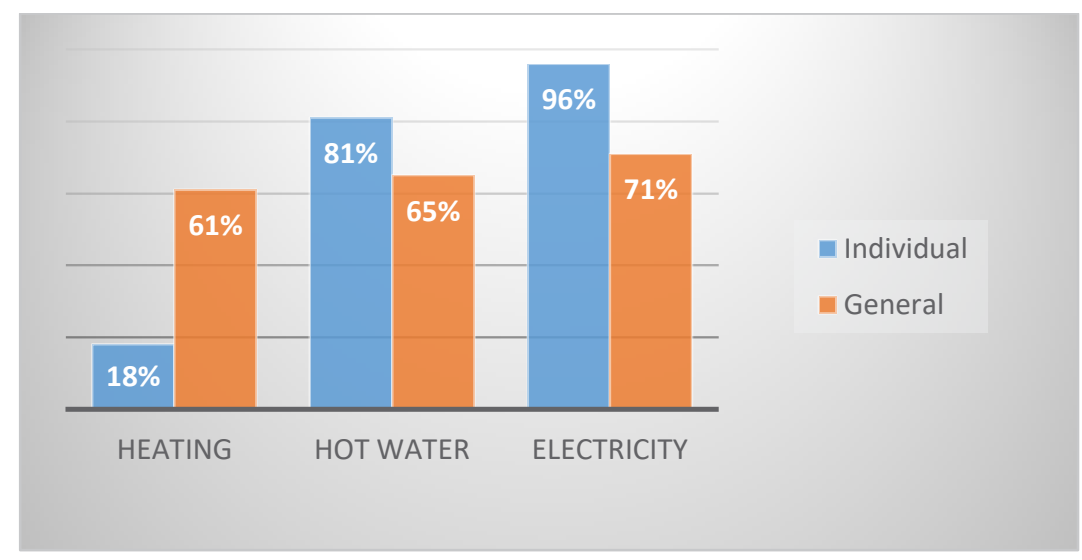

Fig. 3. Level of MRB equipment with energy metering devices, percent

\section{Structure of energy consumption for non-heating needs}


This section will show the structure of energy consumption in apartment buildings, with the exception of heating. A comparative description of consumption in comparison with other countries will be given. Data for Russia and some other countries are based on CENEF XXI calculations [16].

\subsection{Hot water supply}

For the purposes of hot water supply per apartment in Russia, an average consumption is $515 \mathrm{~kg}$ of conventional fuel per year, in the US - 342, on average in the EU - 230, in Japan - 205 [17]. High Russian indicators are explained by the lower efficiency of using hot water and water heating equipment.

In terms of the specific energy consumption for hot water supply per $1 \mathrm{~m} 2$ of apartment space, Russia is also quite wasteful. This is partly due to the lower availability of living space. Since the consumption of hot water depends on the number of residents, the smaller the living area per inhabitant, the higher the specific consumption per $1 \mathrm{~m} 2$.

The average daily consumption is about 70 liters / person - about 55-60 kW per person / $\mathrm{m} 2$ per year, depending on the availability of living space.

\subsection{Cooking}

Food preparation in Russia accounts for $7.7 \%$ of all energy consumed in the residential sector. In the EU, these goals account for an average of $10 \%$ of energy consumption, with a range from $3 \%$ in Denmark to $30 \%$ in Romania [18]. In the US, about 3-4\% is spent for this purpose. In Russia, these purposes account for $29 \mathrm{kWh} / \mathrm{m} 2$ per year, and in the United States-5.7 kWh / m2 per year. Here again, the main difference is due to the lower availability of residential space in Russia, which is many times lower than in the United States. The development of the public catering system and the efficiency of gas and electric stoves also play an important role.

\subsection{Lighting}

Lighting accounts for about $12.6 \%$ of residential electricity consumption in Russia. In developed countries such as Germany or France, this share is $12-15 \%$ [19]. In the United States, lighting accounts for $10 \%$ of all residential electricity consumption. In India, depending on the season $-9-14 \%$ of electricity consumption. In the EU, the annual electricity consumption per household for lighting purposes varies markedly: in Slovakia, $180 \mathrm{kWh}$ per year, in Germany - about 280, in France-400, in Cyprus up to $900 \mathrm{kWh}$ per year [20]. In Russia, according to the CENEf, it is equal to $340 \mathrm{kWh}$ per year, and in the United States - 1,550.

\subsection{Conditioning}

The condition for a comfortable stay in the climatic conditions of Russia, even in the middle zone, not to mention the southern regions, is the presence of air conditioning. In 2012, there were 12 air conditioners per 100 households in Russia. In the cities the share of the security according to the air conditioning equipment is significantly higher. In Italy, $33 \%$ of households are equipped with them, in Spain-55\%, in Greece-98 \%. In countries such as Germany or the Netherlands, the air-conditioning coverage does not exceed 3-5\%.

Electricity consumption for air conditioning needs largely depends on weather conditions: the number of degree-days of the cooling period.A comparison of the specific 
electricity consumption for air conditioning shows that in Russia in 2011-2012 it was only 0.8-1.7 $\mathrm{kWh} / \mathrm{m} 2$ per year, in Canada - 3.6, and in the United States-14.7. The highest consumption per household for these purposes in the EU is in Cyprus: $670 \mathrm{kWh}$ per household per year.

\subsection{Electrical appliances}

Consumption in Russia by household appliances reaches $27.1 \mathrm{kWh} / \mathrm{m} 2$ per year (excluding lighting, cooking, hot water and electric heating). In the UK, this figure is slightly lower: $25.7 \mathrm{kWh} / \mathrm{m} 2$ per year, in Canada - 26.5; in Finland-37.3 (one of the highest rates in Europe), and in the US-49.3.

The main major electrical appliances analyzed are refrigerators and freezers, as well as washing machines. According to CENEf estimates, refrigerators and freezers account for $22.5 \%$ of household electricity consumption in Russia. Their provision per 100 households in 2012 reached 125 PCs.

\section{Conclusiones}

The level of energy consumption in multi-family residential buildings in Russia exceeds the average of similar indicators in European countries. Russia has a great potential to reduce energy consumption in this area. Unfortunately, the measures that the state is currently taking to solve this problem are insufficient.

The main reasons for the high energy consumption of residential multi-apartment buildings in Russia are insufficient motivation of developers in the construction of new buildings with a high energy efficiency class, insufficient number of metering devices for energy spent on heating buildings, weak automation of heating systems. The main solution to the problem may be more active state support for energy-efficient technologies, compensation for excessive costs of the developer associated with increasing the energy efficiency class in the construction of new buildings. In addition, financial support is required for companies engaged in the reconstruction and repair of old houses with a low energy efficiency class.

\section{References}

[1] Aleksandr Lanko, Francisco José Sánchez de la Flor, Tamara Narezhnaya, A review on buildings energy consumption in Russia: educational buildings, E3S Web of Conferences 164(11):02001, DOI: 10.1051/e3sconf/202016402001.

[2] Center for Energy Efficiency official website http://www.cenef.ru/art 11207_114.html (accessed 15 October 2020)

[3] Energy Efficiency Trends and Policies in the Household and Tertiary Sectors https://www.odyssee-mure.eu (accessed 06 October 2020)

[4] EU Buildings Database https://ec.europa.eu/energy/eu-buildings-database en (accessed 12 October 2020)

[5] U.S. Energy Information Administration's (EIA) https://www.eia.gov/ (accessed 12 October 2020)

[6] Official website of the Government statistics https://www.fedstat.ru/form/10072 (accessed 12 October 2020) 
[7] State report on the state of energy saving and improving energy efficiency in the Russian Federation in 2016 https://minenergo.gov.ru/node/5197 (accessed 12 October 2020)

[8] The energy efficiency rating of constituent entities of the Russian Federation (2017) https://minenergo.gov.ru/node/5197

[9] The energy efficiency rating of constituent entities of the Russian Federation (2016) https://minenergo.gov.ru/node/5197

[10] State report on the state of energy saving and improving energy efficiency in the Russian Federation in 2015 https://minenergo.gov.ru/node/5197

[11] State report on the state of energy saving and improving energy efficiency in the Russian Federation in 2014 https://minenergo.gov.ru/node/5197

[12] Forms of providing information for the rating of heat supply efficiency https://minenergo.gov.ru/node/5197

[13] State report on the state of energy saving and improving energy efficiency in the Russian

Federation https://www.economy.gov.ru/material/dokumenty/gosudarstvennyy_doklad_po_energoeffe ktivnosti_.html

[14] State report on the state of energy saving and improving energy efficiency in the $\begin{array}{llll}\text { Russian } & \text { Federation in } & 2017\end{array}$ https://www.economy.gov.ru/material/dokumenty/gosudarstvennyy_doklad_po_energoeffe ktivnosti_.html

[15] Monitoring the implementation of state programs of the Russian Federation for the I-II quarters of 2018 https://www.economy.gov.ru/material/dokumenty/monitoring_realizacii_gosudarstvennyh programm_rossiyskoy federacii_za iii kvartaly_2018 goda.html

[16] I. A. Bashmakov, Energy efficiency of buildings in Russia and abroad,

Energosberejenie 4/2015, Avok

[17] Global Energy Assessment. Towards a Sustainable Future. IIASA. Austria. 2012.

[18] B. Lapillonne, Energy efficiency in buildings: main findings, Energy Efficiency

Trends in Buildings in the EU. Copenhagen, 2012;

[19] Explanatory Factors Assessment. Enerdata. For ADEME. June 2012.

[20] Energy Efficiency Trends in Buildings in the EU. ODYSSEE MURE project, 2012 